\title{
Constrained Momentum Investment
}

\author{
Marcus Davidsson \\ Nygatan 17 \\ 55316 Jonkoping \\ Sweden \\ E-mail: davidsson_marcus@hotmail.com
}

Received: December 5, 2011

Accepted: January 5, 2012 Published: April 15, 2012

doi:10.5430/ijfr.v3n2p69

URL: http://dx.doi.org/10.5430/ijfr.v3n2p69

\begin{abstract}
The previous literature on momentum investments has only considered the so called unconstrained momentum return. This paper will investigate budget constrained momentum returns by using two different datasets. The conclusion is that unconstrained momentum returns systematically overestimate the positive returns and underestimates the negative returns. This has not previously been understood. Such a result has important implications for applied portfolio investments and the attractiveness of such strategy.
\end{abstract}

Keywords: Momentum Investment, Expected Return, Portfolio Theory

\section{Introduction and Literature Review}

Momentum investing has been investigated by many authors. One of the most famous studies was done by Jegadeesh \& Titman (1993). The authors investigated a dataset from 1965 to 1989 where the investor ranked stocks according to their return during the last six months. The investor then takes a long position in the stocks that have outperformed and hold such positions for the next six months. They found that such an investor would on average have made a twelve percentage annual return. Such return premium could be explained by a simple random walk model or more specifically the expected return component in such a model. Over the short time horizon the return is driven by the return noise but over time the expected return accounts for a large fraction of the return i.e. the momentum return. The investor also has to be aware of the fact that changes in expected return can occur at any point. However, the investor seems to be able to generate abnormal return despite such a phenomenon. This is also supported by George and Hwang (2004) who found that the 52-week high price explains a large portion of the profits from momentum investing and that the future return forecast based upon the 52-week high does not reverse in the long run. It is also interesting to note that authors such as Conrad \& Kaul (1988) has found that expected return are positive serial correlated while Runde \& Kramer (1991) found that the return noise is serial independent. Such positive serial correlated expected return could also be an explanatory factor for the abnormal momentum return.

Lui, Strong \& Xu (1999) use a different dataset from the period 1977 to 1998 for the UK. The authors find evidence of significant momentum profits for the sample of UK stocks. They controlled for factors like firm size, stock price, book-to-market ratio, and cash earnings-to-price ratio which could not explain the momentum returns. The authors concludes that the momentum returns found in the empirical analysis was due to the fact that markets tend to under react to firm specific information. Authors such as DeLong, Shleifer, Summers, Waldmann (1990) offer an alternative explanation to the momentum profits. The authors explain that when we have positive feedback traders such as trend traders who buy stocks when the price increases and sell when the price decrease then "rational" speculation can have a destabilising effect on price i.e. deviating far from fundamental value. They argue that when "rational" speculators, which are represented by fundamental traders, get good news then they buy that particular stock. Since they anticipate that the positive feedback traders will also buy that stock in the next day, they buy more that is warranted by the fundamental news hence pushing up prices even more from fundamental value. The weakness with such an argument is the notion that there exists a "fair" market price that should reflect some fundamental value. Since the market sets the prices, such fair price does not exist. The market always correctly determines what a stock is worth at any point in time.

Hong, Lim \& Stein (2000) use a gradual-information-diffusion model to investigate momentum returns. The authors find that the profitability of the momentum investment strategy declines with firm size. They also found that the momentum investment strategy worked better for stocks with low analyst coverage. This is especially true for past losers 
than for past winners. They conclude that such findings are consistence with the notion that firm-specific bad news only spreads gradually across the investing public. Grinblatt, Titman, and Wermers (1995) used a quarterly dataset for mutual funds for the period 1974 to 1984 to investigate how popular the momentum investment strategy was. The authors found that 77 percent of the mutual funds under investigation used a momentum investment strategy i.e. buying past winners. They also found that the mutual funds did not to the same extent sell past losers. Such momentum funds did also have better performance compared to other non-momentum funds. Pettengill, Edwards and Schmitt (2006) argue that the momentum investment strategy is not equally profitable for professional investors and individual investors. They found evidence that professional investors tend to be more disciplined and well informed which results in a higher profitability compared to the individual investors. Further, in Rouwenhorst (1998) study a diversified long momentum portfolio outperformed a diversified short momentum portfolio with more than one percent per months, after adjusting for risk. There also exist other studies that have looked at the momentum investment strategy from a little more critical perspective.

Lesmond, Schill and Zhou (2004) examined the profitability of the momentum investment strategy i.e. buying past winners and selling past losers based upon stock market data for the period 1980-1998. They argue that the momentum investment strategy require trading in securities that have a disproportional high trading cost. The authors explain that such trading and transaction costs prevent profitable strategy execution. This means that the momentum investing strategy should not unconditionally be branded as the wholly grail of investment strategies but rather be approached with a bit more of prudence. The authors also point out that there might exist profitable momentum investment strategies but that not all momentum strategies will be profitable. The purpose of this paper is to investigate where the truth lies when it comes to the profitability of the popular momentum investment strategy.

\section{Modeling Framework and Simulated Data}

There exist three main ways to calculate returns; simple return, percentage return and log return (Brooks, 2008). We will use the first method for convenience. The return for our investment strategies is simply calculated as the difference between the price at time $t+1$ and time $t$. The initial portfolio value plus the return series is then added together to get the value of the portfolio in the last period. The initial portfolio value is assumed to be ten thousands. The percentage difference between the initial portfolio value and the portfolio value in the last period is then calculated. The first investment strategy that we are going to consider is a pure long momentum strategy. The investor simply buys the stock that has outperformed the most during the last period. The portfolio value at time $t \mathrm{PV}[\mathrm{t}]$ is given by the portfolio value in the previous period PV[t-1] plus the return at time $t$ of the stock that had the highest return in the previous period $\mathrm{RR}[\mathrm{t}, \mathrm{w} 2[\mathrm{t}-1]]$ as seen below:

$$
P V[t]=P V[t-1]+R R[t, w 2[t-1]]
$$

It is important to note that such investment strategy represent the unconstrained momentum case i.e. the investor buys one share of each stock regardless of what the current value of his portfolio is. The second investment strategy that we are going to consider is the constrained long momentum strategy. This is a more realistic strategy since the investor is constrained by the value of his portfolio in the previous period ie if the portfolio value in the previous period was 100 then he can only buy one-tenth of a stock that costs 1000 . Hence, the modelling becomes more realistic. The portfolio value at time $\mathrm{PV}[\mathrm{t}]$ is given by the portfolio value in the previous period $\mathrm{PV}[\mathrm{t}-1]$ plus the ratio between the portfolio value in the previous period PV[t-1] and the stock price in this period Data[t,w2[t-1]+1] multiplied by the return at time $\mathrm{t}$ of the stock that had the highest return in the previous period $R R[\mathrm{t}, \mathrm{w} 2[\mathrm{i}-1]]$ as seen below:

$$
P V[t]=P V[t-1]+\frac{P V[t-1]}{D a t a[t, w 2[t-1]+1]} * R R[t, w 2[t-1]]
$$

Note that Data[t,w2[t-1]+1] is simply a matrix with stock prices where the first column is the date hence we have to add one to get the correct column for that particular stock index. The formula for the annualized percentage can be seen below. We solve the below expression for $\mathrm{x}$ and multiply by 100 to get the annualized percentage return where $\mathrm{n}$ is the number of years in the dataset and NR is the number of rows in the data matrix i.e. number of observations.

$$
P V[N R]=P V[1] *(1+x)^{n}
$$

We can start by simulating some data and look how our investment strategies have performed. We simulate 100 random trajectories each with 200 observations. We assume that the starting price is randomly determined and is different for all the stocks. The standard deviation and expected return is also randomly determined. The standard deviation can vary between 1 and 10 and the expected return can vary between -1 and 1 . We can see in Figure 1 that the annualized percentage return for the unconstrained momentum strategy is -0.18 and for the unconstrained momentum strategy the annualized percentage return is -2.64 . 


\section{Modeling Framework and Empirical Data}

We can now look how these two investment strategies; unconstrained momentum and constrained momentum strategies have performed for two different empirical datasets. The first dataset that we are going to look at is a monthly data set based upon 23 global stock markets from the period 1997 to 2010 . The percentage expected value (EV) and the standard deviation of returns for each market can be found in Table 1. We can also see the price plot of the different markets. The last expression for the annualized return is also now raised by 13 since there are thirteen years between 1997-2010. We can see in Figure 3 that the unconstrained momentum strategy had an annualized return of 19 percent while the constrained momentum strategy only had an annualized return of 6.6 percent. This means that previous research have overestimated the significance of momentum returns. An investor that is willing to deposit his capital for a long time with a long term government bond most likely will receive a risk free annual return in the ballpark of 3 percent per year. A momentum strategy, which has significant more risk than government bonds, only manages to offer an investor a three percent risk premium. Such risk premium is way too low to compensate for the added risk the investor has to take on.

The second dataset that we are going to look at is a daily data set based upon approximately 500 SP500 stocks from the period 2005 to 2010. The percentage expected value (EV) and the standard deviation of returns for a sample of stocks can be found in Table 2. The portfolio value for the unconstrained and constrained momentum investment strategy is calculated the same way as in the previous example with reservation for the increase in the number of observations. The last expression for the annualized return is also now raised by 5 since we have five years between 2005-2010. We can see in Figure 5 that the unconstrained momentum strategy had an annualized return of -0.69 percent while the constrained momentum strategy had an annualized return of -9.7 percent. This again means that previous research have overestimated the significance of momentum returns. An investor that is faced with a fix budget constraint which most investors are will have a much worst performance than a simple equal weighted momentum portfolio. This has not been documented before. We can also do some further analysis on our daily data set for the SP500 stocks from 2005 to 2010. We can introduce a time dimension i.e. will our unconstrained momentum return change if consider daily, weekly or monthly returns?! We can also benchmark such returns against the means reversion return. Such an analysis is done by introducing a "slicer procedure". The user specifies a return matrix RR and a lag parameter i.e. for a one day momentum investment strategy the lag parameter is one. The benefit of such a procedure is that it is very flexible when it comes to outputting return series that has specific characteristics like daily or month returns. Since we are using percentage return this time we have to compound our returns over time as seen below. The portfolio value over time evolves according to the below equation where data2[t] is simply the return at time $t$. This means that the portfolio value grows exponentially over time i.e. a large return grow faster than a small return. We also assume that the return index or in this case portfolio value at time one is equal to 100. We can see in Figure 6 the time dimension of our unconstrained momentum returns.

$P V[t]=P V[t-1] *\left[1+\frac{\text { data } 2[t]}{100}\right]$

We can also see the mean reversion strategy which is simply the negative of the momentum return ie when the momentum strategy is making money the mean reversion strategy is losing money. It appears that for the 1-day dynamic trading strategy the momentum strategy initially performs very well however there seem to exist a trend-break around 2007 where such a strategy stops to work. We can also see that the mean-reversion strategy performance is bad for the whole sample period for the 1-day dynamic trading. For the 5-day dynamic trading strategy the momentum strategy performance is bad for the whole sample period. The mean-reversion strategy performance is equally bad however there again seem to exit a trend-break around 2008. After such a trend-break the performance of the mean-reversion strategy is increased. For the 25-day dynamic trading strategy the momentum strategy performance is better and the mean-reversion performance is worse.

\section{Conclusion and Final Discussion}

We started this paper by reviewing the literature related to momentum investment. We saw that many separate studies have found a positive return premium associated with momentum investing. We also discussed the potential theoretical explanations for such return premium. We then introduced the notion of unconstrained and constrained momentum returns. We showed that the unconstrained momentum return does not represent realistic investor returns. This has to do with the fact that every investor is faced with a fixed budget constraint which means that all momentum opportunities are not real opportunities. We saw that unconstrained returns over estimate the return derived from a momentum strategy based upon global stock market index data and under estimate the negative return derived from a momentum strategy based upon SP500 stocks. Such finding has important implications for applied portfolio investments. We then introduced the notion that our unconstrained momentum returns might have a time dimension. This was also true, since 
our unconstrained momentum return changes radically depending on which return interval we considered i.e. daily, weekly or monthly. We also looked at the mean reversion return for comparison purposes. We have in appendix-1 further illustrated the empirical return of a diversified momentum investment strategy.

\section{References}

Brooks, C. (2008). Introductory Econometrics for Finance, Second Edition, Cambridge University Press

Conrad, J. \& Kaul, G. (1988). Time-Variation in Expected Returns, Journal of Business, Vol. 61, No. 4, pp. 409-425.

DeLong, B., Shleifer, A., Summers, L. \& Waldmann, R. (1990). Positive-Feedback Investment Strategies and Destabilizing Rational Speculation, Journal of Finance, vol 45, issue 2, pp 374-397

George, T. \& Hwang, C. (2004). The 52-Week High and Momentum Investing, The Journal of Finance, vol. 59, No. 5, pp. 2145-2176

Grinblatt, M., Titman, S. \& Wermers, R. (1995). Momentum Investment Strategies, Portfolio Performance, and Herding: A Study of Mutual Fund Behavior, American Economic Review, vol 85, issue 5, pp 1088-1105

Hong, H. Lim, T. \& Stein, J. (2000). Bad News Travels Slowly: Size, Analyst Coverage, and the Profitability of Momentum Strategies, Journal of Finance, vol 55, issue 1, pp 265-295

Jegadeesh, N. \& Titman, S. (1993). Returns to buying winners and selling losers,Journal of Finance 48, 65-91

Lesmond, D, Schill, M. \& Zhou, C. (2004). The Illusory Nature of Momentum Profits, Journal of Financial Economics, vol. 71, no. 2, pp. 349-380.

Lui, W., Strong, N. \& Xu, X. (1999). The Profitability of Momentum Investing, Journal of Business Finance \& Accounting, vol 26, issue 9-10, pp 1043-1091

Pettengill, G., Edwards, S. \& Schmitt, D. (2006). Is Momentum Investing a Viable Strategy for Individual Investors?, Financial Services Review, Vol.15, pp. 181-197.

Rouwenhorst, K. (1998). International momentum strategies, Journal of Finance, vol 53, issue 1, pp 267 - 284

Runde, R. \& Kramer, W. (1991). Testing for autocorrelation among common stock returns, Statistical Papers, Vol 32, No 1, pp 311-322

Table 1. Global Stock Markets from 1997-2010

\begin{tabular}{|c|c|c|c|c|c|c|c|c|c|}
\hline Ticker & $\wedge \mathrm{AEX}$ & ${ }^{\wedge} \mathrm{AORD}$ & $\wedge$ ATX & ${ }^{\wedge} \mathrm{BSESN}$ & ${ }^{\wedge} \mathrm{BVSP}$ & ${ }^{\wedge} \mathrm{CCSI}$ & ${ }^{\wedge} \mathrm{DJI}$ & ${ }^{\wedge} \mathrm{FCHI}$ & $\wedge^{\wedge} \mathrm{FTSE}$ \\
\hline EV (\%) & -0.25 & 0.39 & 0.53 & 1.24 & 1.52 & 1.08 & 0.24 & 0.26 & 0.13 \\
\hline SD & 7.19 & 3.94 & 6.49 & 7.90 & 9.51 & 5.93 & 4.68 & 5.87 & 4.40 \\
\hline Ticker & ${ }^{\wedge} \mathrm{GDAXI}$ & $\wedge^{\wedge} \mathrm{GSPC}$ & ${ }^{\wedge} \mathrm{HSI}$ & ${ }^{\wedge} \mathrm{JKSE}$ & ${ }^{\wedge} \mathrm{KLSE}$ & ${ }^{\wedge} \mathrm{KS} 11$ & ^MERV & ${ }^{\wedge} \mathrm{MXX}$ & ${ }^{\wedge} \mathrm{N} 225$ \\
\hline EV (\%) & 0.43 & 0.18 & 0.47 & 1.38 & 0.51 & 1.04 & 1.31 & 1.46 & -0.32 \\
\hline SD & 6.89 & 4.76 & 7.99 & 9.30 & 8.01 & 9.95 & 11.40 & 7.33 & 5.90 \\
\hline Ticker & ${ }^{\wedge} \mathrm{SSEC}$ & $\wedge^{\wedge} \mathrm{SSMI}$ & $\wedge^{\wedge} \mathrm{STI}$ & ${ }^{\wedge} \mathrm{TA} 100$ & ${ }^{\wedge} \mathrm{TW} 11$ & & & & \\
\hline EV (\%) & 0.86 & 0.15 & 0.56 & 1.00 & 0.15 & & & & \\
\hline SD & 8.49 & 4.93 & 7.93 & 6.34 & 7.92 & & & & \\
\hline
\end{tabular}


Table 2. Sample of SP500 Stocks from 2005-2010

\begin{tabular}{|c|c|c|c|c|c|c|c|c|c|}
\hline Name & $3 \mathrm{M}$ & AES & AFLAC & AK STEEL & HLDG & AT\&T & ABBOTT & ABER & ADOBE \\
\hline EV (\%) & -0.01 & 0.04 & 0.03 & 0.31 & 0.10 & -0.03 & -0.02 & 0.19 & 0.47 \\
\hline SD & 0.85 & 1.59 & 1.02 & 3.89 & 0.83 & 1.34 & 2.26 & 2.08 & 2.64 \\
\hline Name & MICRO & AETNA & AGIL & AIR & AIRG & AKAM & ALCOA & ALL & ALLT \\
\hline EV (\%) & 0.13 & 0.21 & 0.04 & 0.25 & 0.42 & 0.07 & 0.19 & 0.47 & 0.15 \\
\hline SD & 1.54 & 1.75 & 1.10 & 1.89 & 2.60 & 1.46 & 1.40 & 2.32 & 1.32 \\
\hline Name & ALLST & ALTE & ALTRI & AMAZON & AMER & & & & \\
\hline EV (\%) & -0.08 & -0.05 & 0.05 & 0.04 & -0.05 & & & & \\
\hline SD & 1.09 & 1.88 & 1.14 & 2.24 & 0.91 & & & & \\
\hline
\end{tabular}

Unconstrained Long Momentum Return

Monthly Rebalancing Strategy Simulated Data

Anualized Percentage Return $=-0.18 \%$

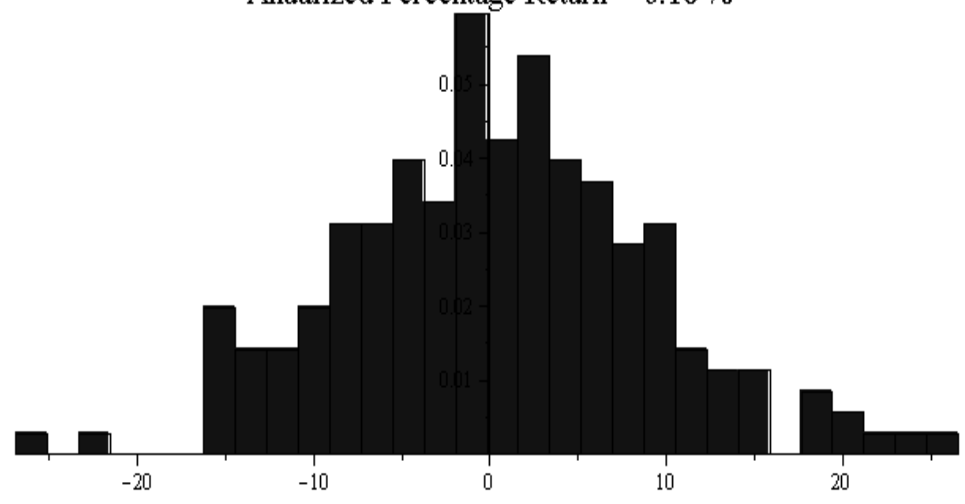

Constrained Long Momentum Return

Monthly Rebalancing Strategy Simulated Data

Anualized Percentage Return $=-2.64 \%$

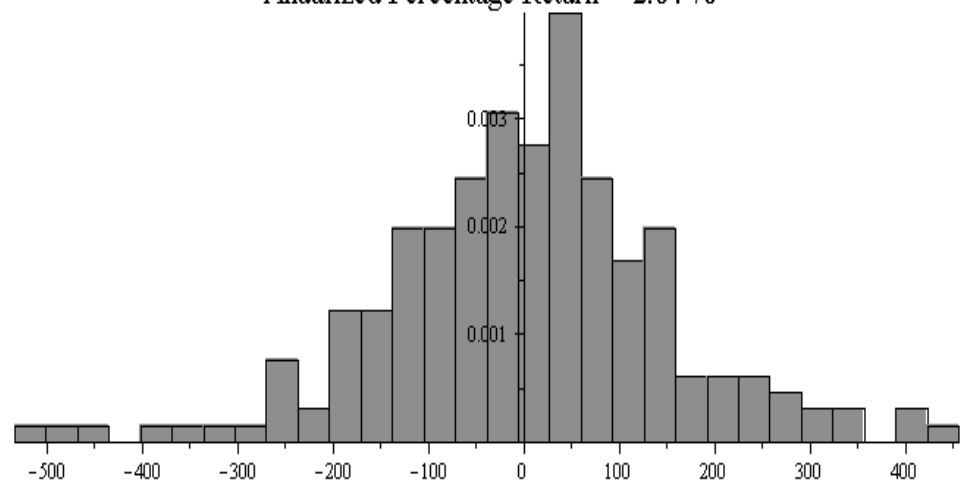

Figure 1. Simulated Data and Long Momentum Return 


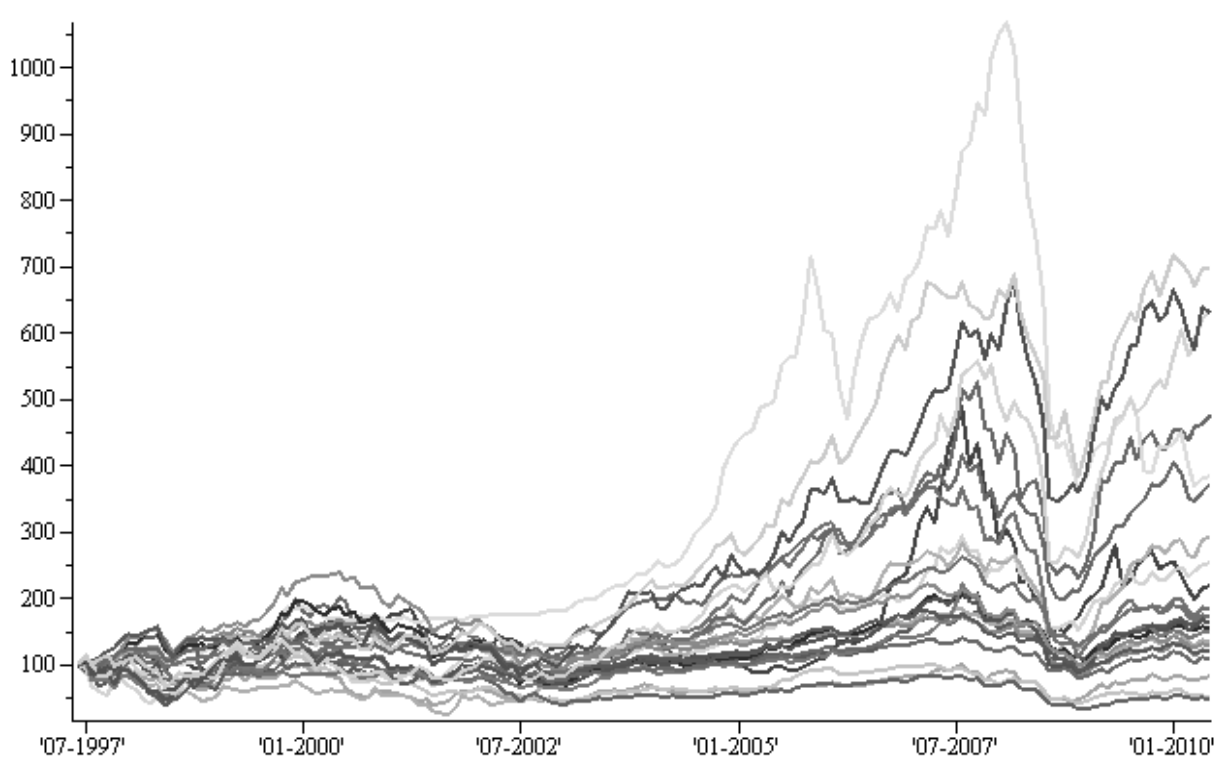

Figure 2. Global Stock Markets from 1997-2010

Unconstrained Long Momentum Return Monthly Rebalancing Strategy Global Stock Markets Anualized Percentage Return $=19 \%$

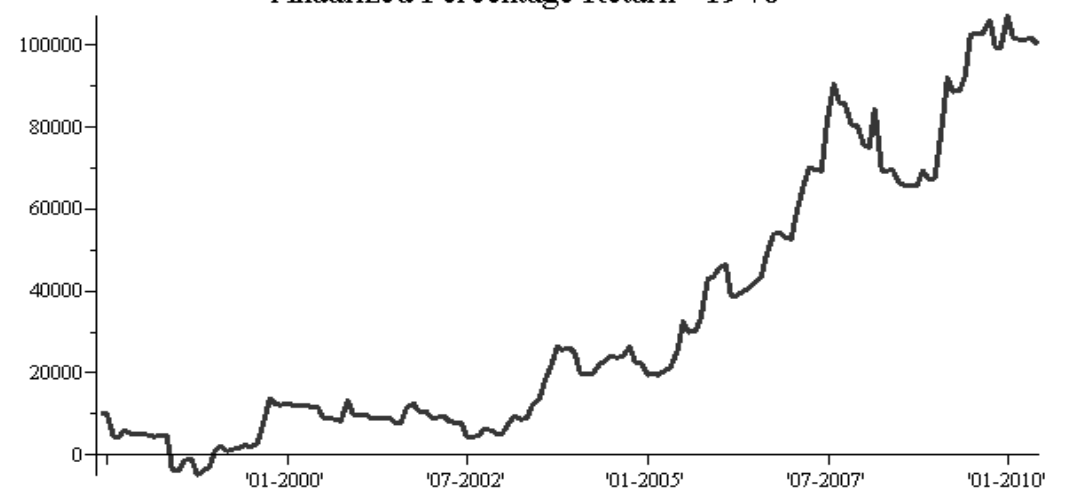

Constrained Long Momentum Return

Monthly Rebalancing Strategy Global Stock Markets

Annualized Percentage Return $=6.6 \%$

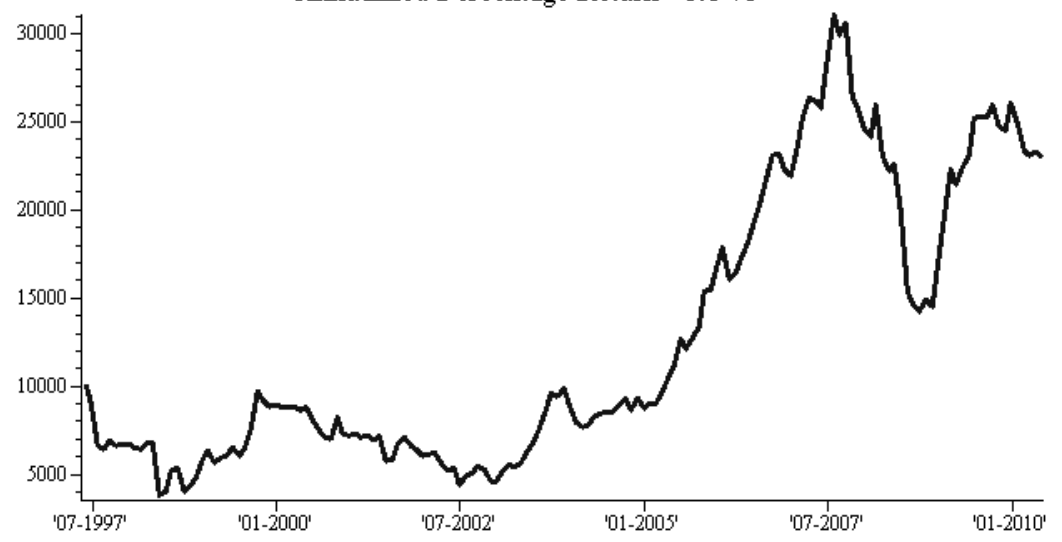

Figure 3. Momentum vs. Constrained Momentum Returns Global Stock Index 


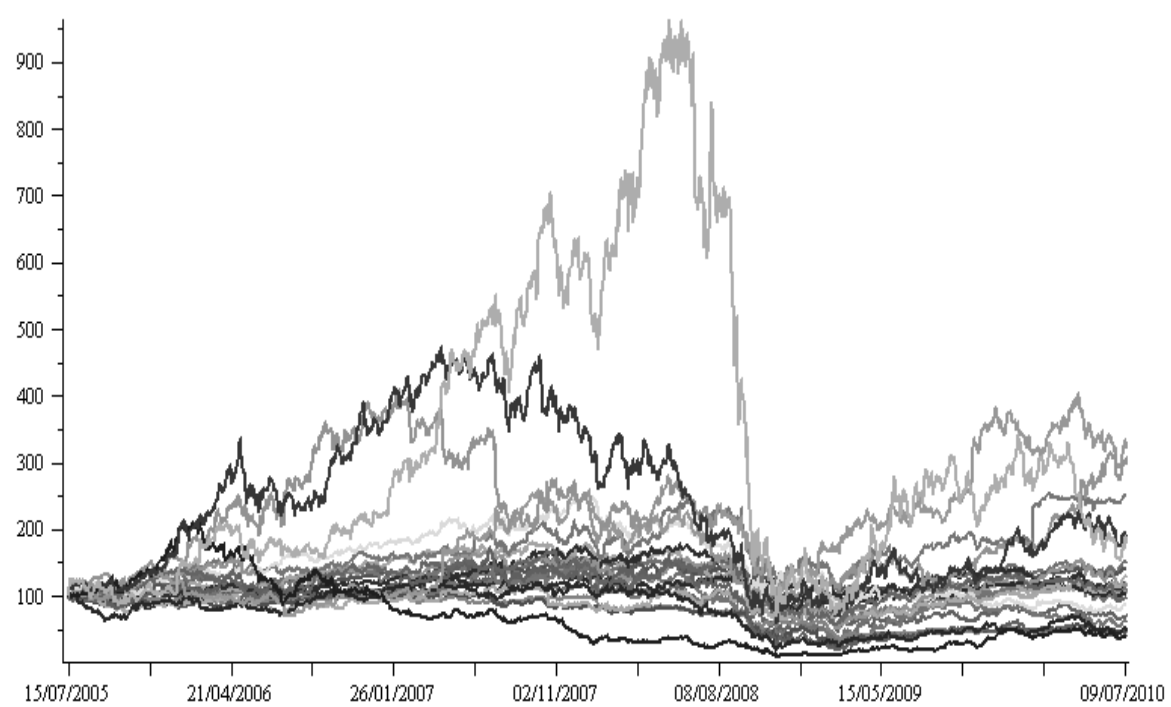

Figure 4. Sample of SP500 Stocks from 2005-2010

Unconstrained Long Momentum Return

Daily Rebalancing Strategy SP500

Anualized Percentage Return $=-0.69 \%$

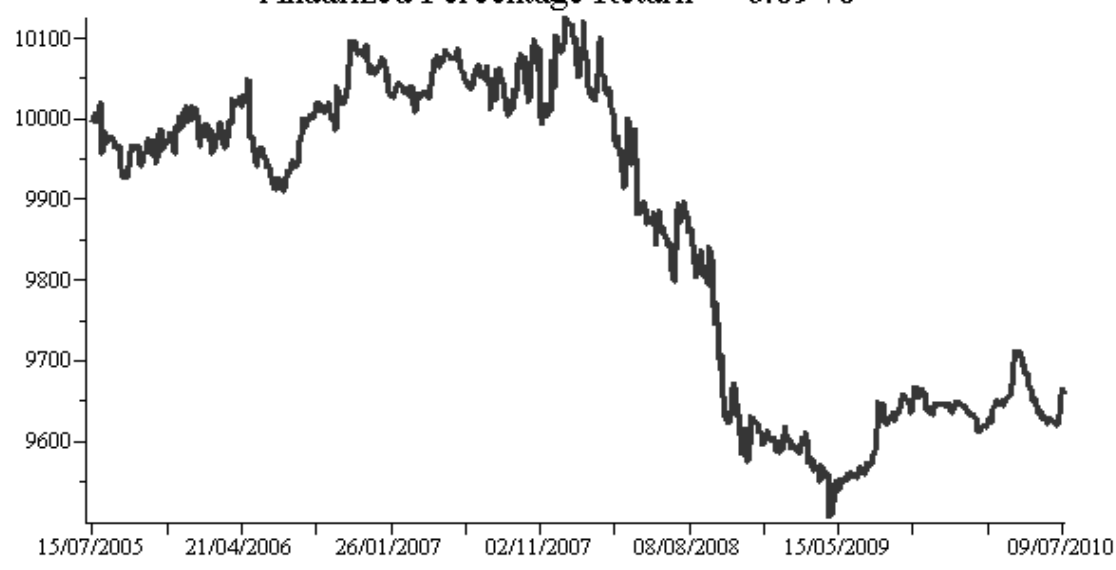

Constrained Long Momentum Return

Daily Rebalancing Strategy SP500

Annualized Percentage Return $=-9.7 \%$

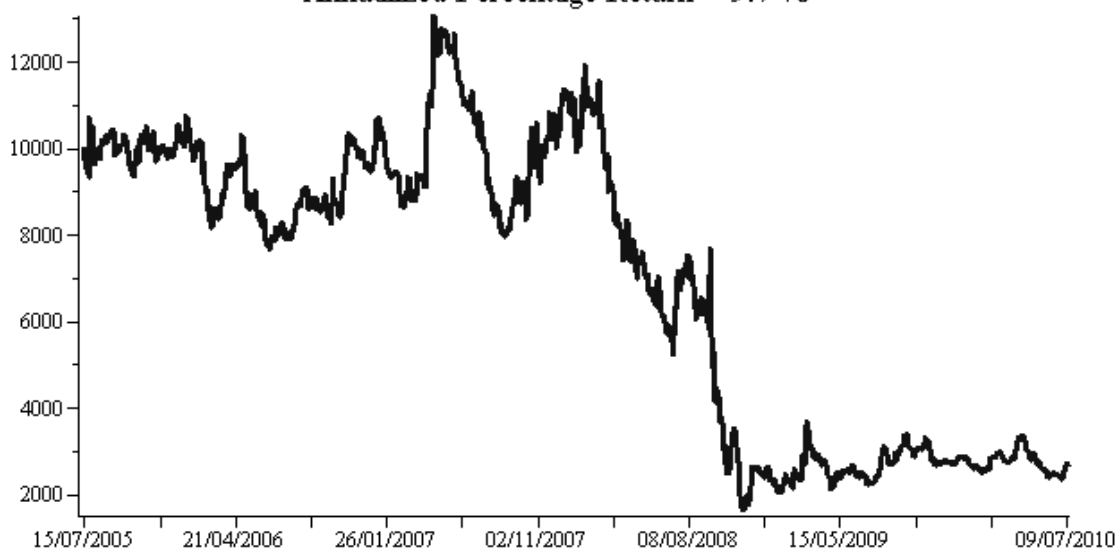

Figure 5. Momentum vs. Constrained Momentum Returns SP500 

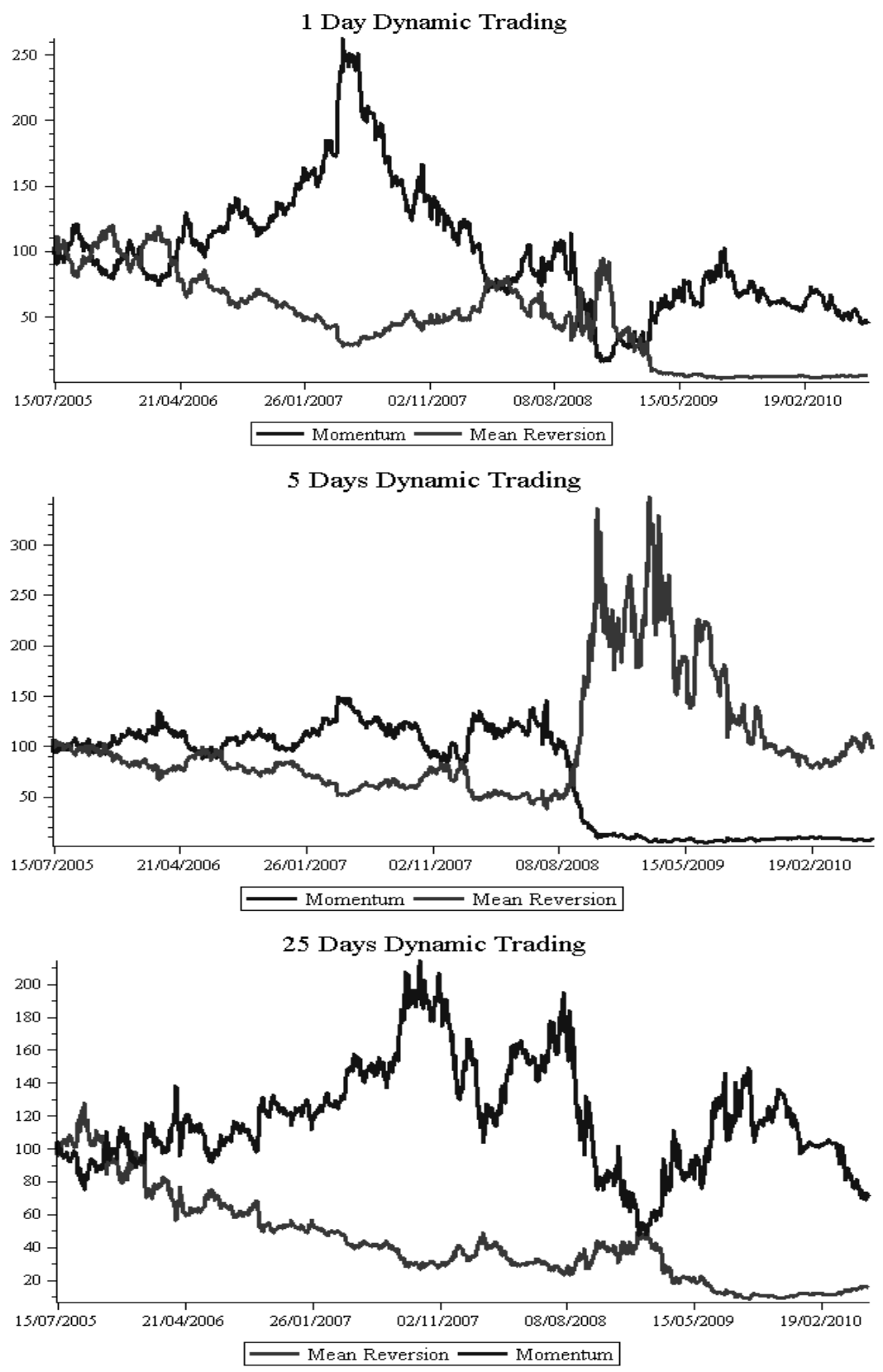

Figure 6. Momentum vs. Mean Reversion Daily SP-500 Data 2005-2010 
Appendix. Further Analysis

Take a long position in the security that outperformed during the last period and on the same time take a short position in the security that has underperformed the most during the last period.

Monthly data from 1997-2010 for 23 global stock market indices

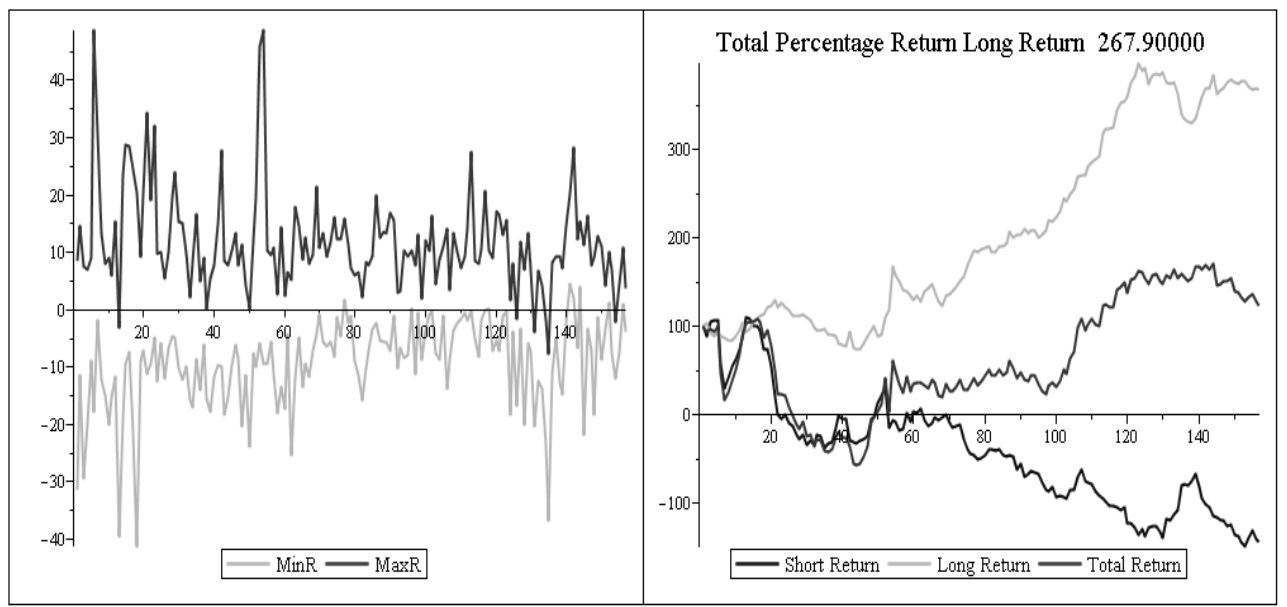

Daily data from 2005-2010 for 478 SP-500 stocks

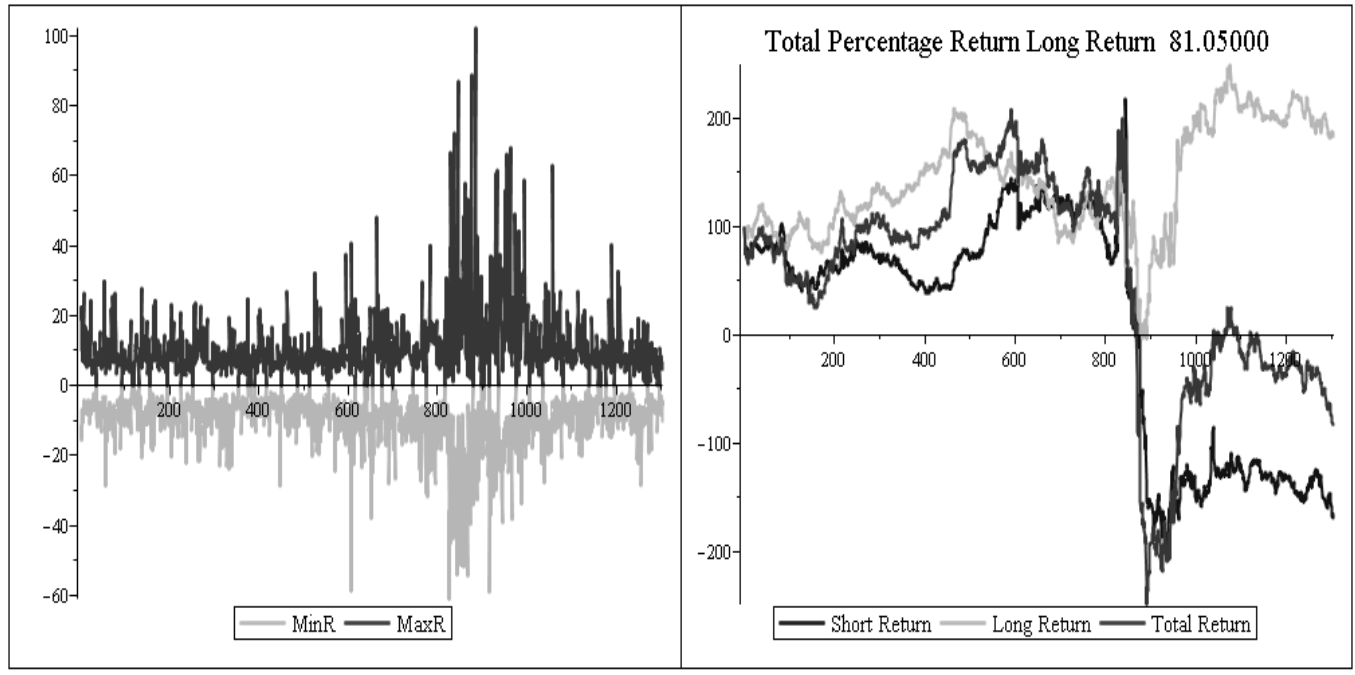

